\title{
Use of In-Class Streaming of Material in Engineering
}

\author{
Caroline R. Kayser, Jennifer J. Amrine, and James A. Swanson
}

University of Cincinnati

\section{Abstract:}

The authors are experimenting with the use of real-time, in-class streaming of lecture materials to portable personal computers that students bring to class. Lecture materials, including audio and visual streams, are saved on both the student and instructor computers in recordings so that class sessions can be reviewed at any time. Students can also take notes electronically. These notes are integrated as part of the session recordings and can be edited during playback. Participants can search their notes for important points and share their notes with other participants. Since the authors prefer to avoid Microsoft PowerPoint presentations in class, they have opted to use a tablet PC during lectures. This material is simultaneously broadcasted to the participants in class (either locally or remotely) and displayed on screens in the front of the classroom. The authors' experiences during a trial use of the technology are presented and discussed.

\section{Introduction and Background:}

Technology is a growing part of our society and it should not be excluded from our classrooms. At one time, overhead projectors were thought of as being high technology. They became a common fixture in classrooms and are now being replaced by computer projectors. Technology is a part of evolution, and as it progresses, academia is faced with keeping pace.

The benefits of utilizing technology in the classroom have been well-documented and supported. Alexander ${ }^{1}$ provides an excellent summary of previously documented e-learning experiences and references Bates' ${ }^{2}$ four reasons for including technology in higher education: (1) improving the quality of learning, (2) improving access to education and training, (3) reducing the costs of education, and (4) improving the cost effectiveness of education. Alexander concluded that for e-learning to be successful in higher education, there must be an excellent university support system for teachers, and teachers must plan and strategize to effectively use technology in the classroom.

At the other end of the spectrum are those who seriously question the use of technology in the classroom. Among several others, Todd Oppenheimer ${ }^{3}$ questions whether a heavy focus on the use of technology in education is actually resulting in a better educational experience for students. Oppenheimer, author of "The Flickering Mind," suggests that educators should approach educational technologies very skeptically. His opinion is that computers are often 
overused since they allow teachers to focus on quantity instead of quality, enabling three "chalkboard lectures" to be crowded into a single PowerPoint presentation. Oppenheimer suggests that computers should be used to supplement current pedagogies instead of replacing them.

Although skeptics of a high-technology approach to teaching at the university level certainly exist, Arnold ${ }^{4}$ stated, "A less hyperbolic and more measured position simply suggests that new modes of communication, new forms of interactive media, and new forms of information representation and information manipulation have not only altered the environment in which universities are situated, but also offer possibilities for improved teaching and learning that academics should not ignore."

\subsection{The University of Cincinnati:}

Like many colleges, the College of Engineering at the University of Cincinnati (UC) is moving in the direction of integrating technology into the learning experiences of our undergraduate students. For several years, UC has required each entering freshman to purchase a portable computer for use on homework assignments and class projects. Portable computers are required instead of desktops so that students can bring them to classes, laboratories, and use them between classes while on campus. In support of the portable PC requirement, UC has invested in a wireless networking infrastructure. Although an early goal was to incorporate the use of PCs into classes, most of the faculty has been slow to modify course content to directly integrate PCs into lectures. Because of this, many students have questioned the requirement of the added expense of a portable PC as opposed to a desktop.

Electronic classrooms are becoming widely accepted in class settings, and often include dedicated data projectors, digital document cameras, VHS or DVD players, and PCs equipped with PowerPoint and other, specialized software. A step above this would be equipping a classroom with an electronic whiteboard capable of displaying computer generated images along with hand-written and hand-drawn images. Often, material displayed, written, and drawn on electronic whiteboards can be printed and/or saved to a file for distribution and/or archiving. Over and above these technologies is the idea of distance learning and harnessing the power of the internet for educational purposes.

The UC College of Engineering recently completed a study funded by the General Electric Foundation in which three learning technologies were evaluated using a conventional chalkboard lecture as a control ${ }^{5}$. The technologies included in the study were remote teleconferencing, a web assisted lecture format, and a web-based streaming-media lecture format. These methods were investigated using two engineering fundamentals courses (Statics and Basic Strength of Materials), which are required of most students in the College of Engineering. During select quarters, the students registering for the classes were divided into four sections where each of the lecturing methods was implemented. In addition to the anecdotal evidence that was collected, student performance in the different sections was cross referenced to their individual learning styles. It was found that students preferred the on-line and streaming media formats to the teleconferencing format by a wide margin. One thing that all of these technologies had in 
common is that they focused on presenting material to the class. In all cases, students still had to take notes in order to have a record of the experience.

A new trend in education is to implement a peer-to-peer learning network wherein information and lecture materials are distributed in real-time to each participant during the lecture. Most often, this format is tailored to the use of presentations created in PowerPoint or similar packages. The primary difference between this technology and those mentioned previously is that there is no need for the students to transcribe the information being presented as it is automatically saved on their PCs. One of these packages is Silicon Chalk.

\section{Silicon Chalk:}

Silicon Chalk is a software package that allows real-time streaming of lecture materials from the instructor's PC to students' computers. Although it was obviously created with PowerPoint presentations in mind, Silicon Chalk works with any type of software running on the instructor's PC (aside from Silicon Chalk, specialized software does not need to be installed on the students' computers). The instructor can broadcast several programs or windows simultaneously including an audio stream, assuming that he or she is using a microphone. Most often, the material is projected at the front of the classroom at the same time that it is broadcasted across the network. Using this package, the lecture is saved on each student's computer as a "recording" that includes the instructor's media stream along with notes that student uses to supplement the presentation. While the software was originally intended for use with wired networks, recent versions of the software have been optimized for use over wireless networks. Other features built in to the technology include:

- The ability for students to ask questions to the instructor electronically. Participants can prepare textual questions during or outside of class. Questions are queued for delivery to the instructor who can respond either during or after class.

- The ability for the instructor to poll the class. Instructors can present questions to participants in different formats (Yes/No, Multiple Choice, Free Response, Etc.). These questions can be prepared ahead of time or during class. The results are summarized and statistics are displayed graphically and presented to participants.

- Students can provide instant feedback indicating their comfort with both the pace and complexity of the presentation. The results are displayed to the instructor in real time, allowing the instructor to respond to the needs of the students.

- Electronic document exchange. Using the integrated "share-box" feature, the instructor can electronically distribute files to participants or accept electronic submissions from students. Students missing a class will automatically receive distributed material during the next session that they attend.

A screen shot of the user interface for Silicon Chalk running in "playback" mode is shown in Figure 1. 


\section{University of Cincinnati Experiences:}

Silicon Chalk has been used in three College of Engineering classes at the University of Cincinnati (UC) over the past year. In the most recent instance, the focus of this paper, a section of Basic Strength of Materials (a fundamental mechanics course) was selected for implementation. The 75-minute classes were held in the afternoon twice a week for 10 weeks. A total of 24 students were enrolled in the section (a second, conventional section taught by another instructor was also offered during the same academic quarter). Students were advised at the beginning of the course that they could either use Silicon Chalk over the wireless network by bringing their laptops to class or could simply take notes from the information projected at the front of the room. Presumably, all students had access to laptop computers since they were required to purchase them when they were freshmen. Since the policy is loosely enforced, however, laptop PCs were loaned to students that did not have one of their own. Since the instructor did not prefer to use PowerPoint presentations, he used a tablet PC so that his handwriting and sketches would be displayed. In the beginning, approximately 12 of the students participated in the lectures using laptop PCs and Silicon Chalk. Near the end of the academic quarter, approximately half of those students were still using Silicon Chalk in the classroom.

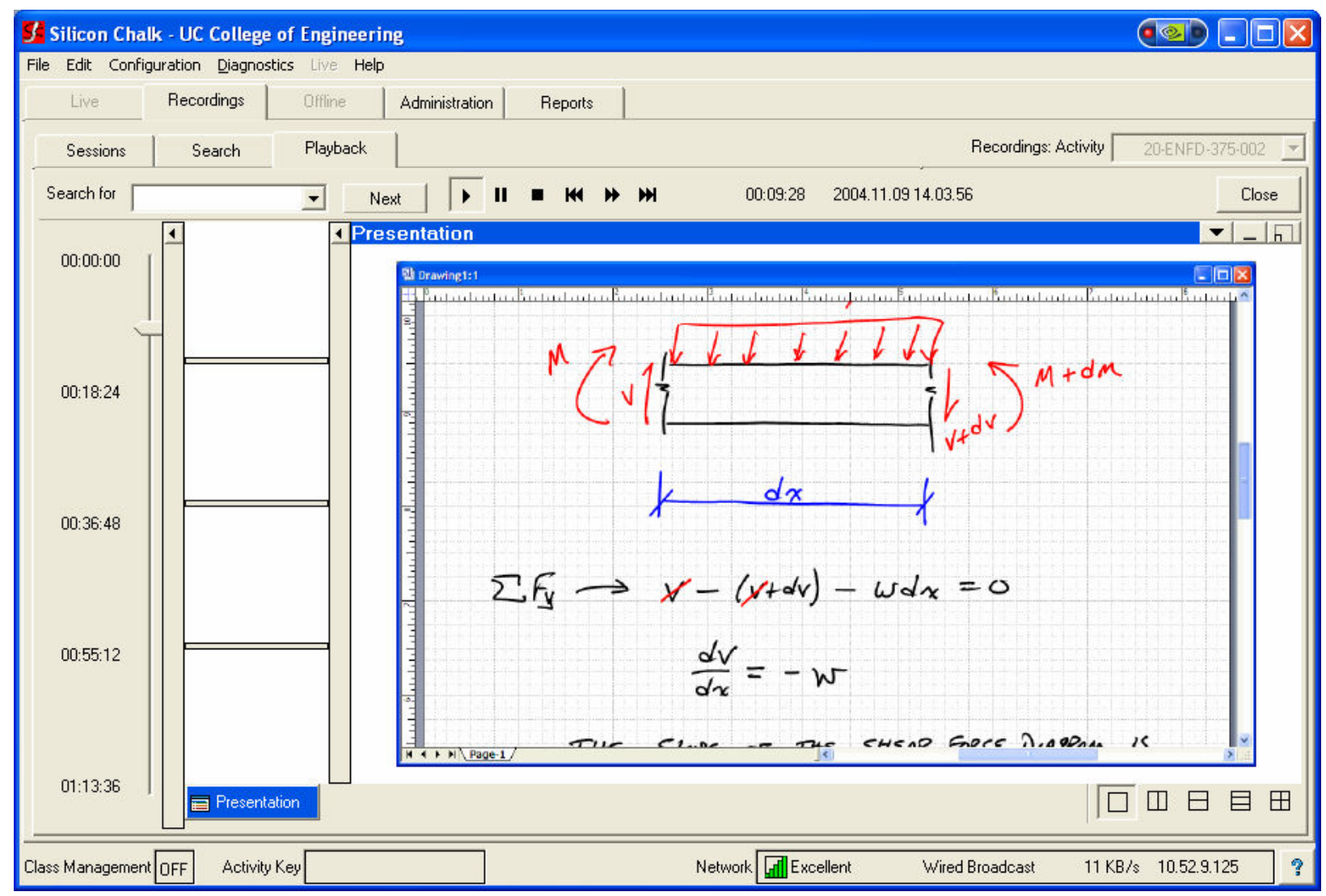

Figure 1: User Interface for Silicon Chalk Running in "Playback" Mode 


\subsection{Technical Information:}

The instructor for the class used an Acer TravelMate tablet PC with a Pentium M processor and $512 \mathrm{MB}$ of RAM as the primary PC running Silicon Chalk in "instructor mode." For most of the lectures, the instructor used Microsoft Visio 2003 - a business CAD package - for "inking" the lecture information. The primary PC was configured in an extended desktop configuration with the primary display streamed through Silicon Chalk and the secondary display projected on one of two screens in the front of the classroom. A second PC, a Dell Latitude with a Pentium 4 processor and $1 \mathrm{~GB}$ of RAM running Silicon Chalk in "student mode" was projected on the second screen. Using this strategy, two full pages could be viewed on one screen while a closeup of the information currently being inked could be viewed on the second screen. Additionally, the instructor was able to show the students how to use different features within Silicon Chalk using his second PC. Brief PowerPoint presentations were used on three occasions. A photo showing the in-class set-up is shown in Figure 2.

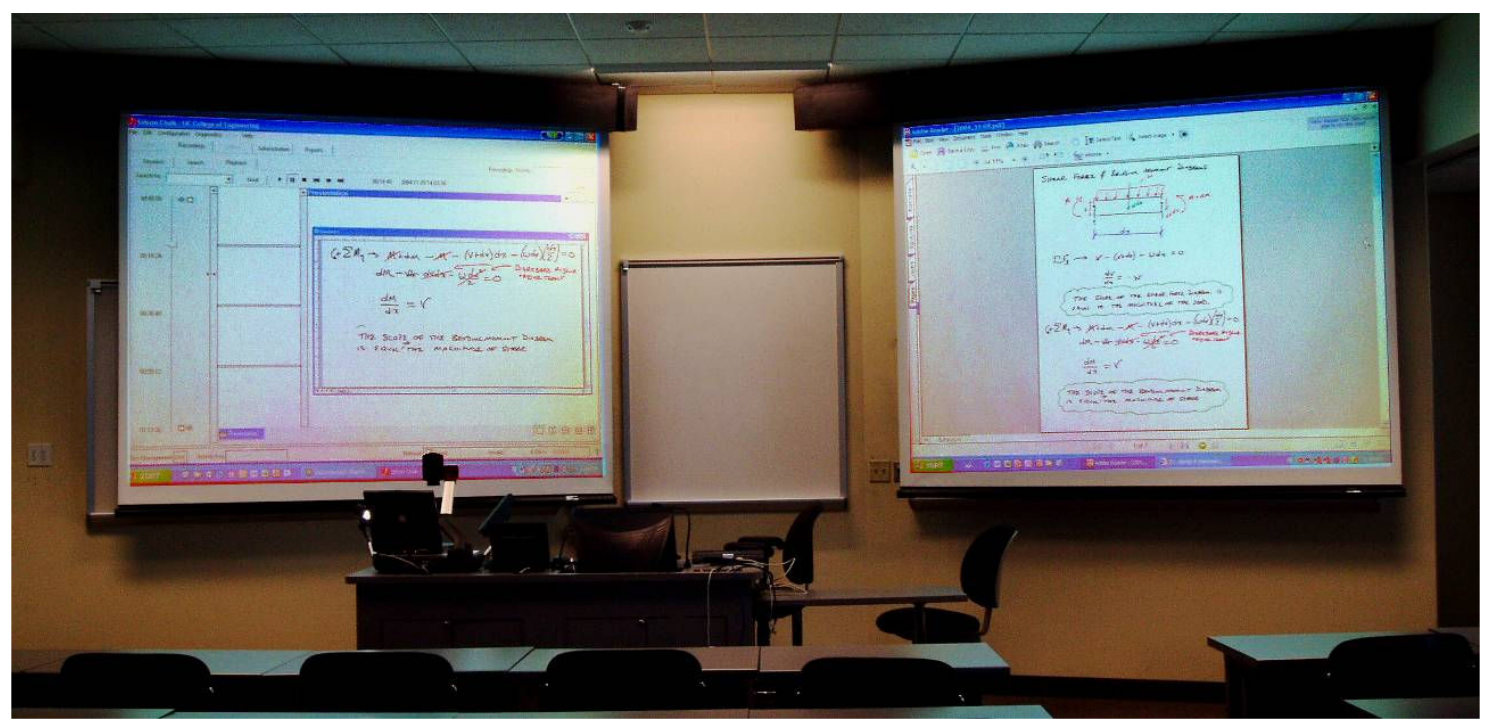

Figure 2: In-Class Set-up of the Computer System

The students used a wide variety of computers, but most were based on Pentium III or Pentium 4 processors with random access memory ranging from $256 \mathrm{MB}$ to $1 \mathrm{~GB}$. All student PCs were equipped with wireless networking. The classroom where the lectures were held was equipped with a wireless network using $802.11 \mathrm{~b}$ protocol. Two different access points could be used depending on where the computers were located within the classroom.

In addition to using Silicon Chalk in the classroom, the instructor maintained a webpage for distribution of class material. Copies of Silicon Chalk recordings were posted along with printouts of the Visio files in PDF format. Completed examples from the instructor's notes that were presented in class were also made available on-line along with homework assignments, homework solutions, and past examinations. Finally, the three PowerPoint presentations were made available in PDF format. 


\subsection{Observations and Comments:}

Several different issues related to the use of the technology in the classroom are presented and discussed in the following paragraphs as strengths and/or weaknesses.

The Instructor Can Face the Class While Writing: Because he was writing on a tablet PC instead of on a whiteboard or chalkboard, the instructor did not need to turn his back to the class. This is a strong positive as students are more engaged and motivated to pay attention when the teacher is facing them. The ability for the instructor to consistently make eye contact with students can help keep students involved, engaged, and interested. It also allows the teacher to see who is keeping up, who looks confused, and who is having difficulty so that he or she can adjust the pace and direction of the class as appropriate. Finally, it enables the teacher to more easily identify students whose minds are wondering so that they can be "pulled back" into the lesson. Lectures are Recorded: As was mentioned earlier, Silicon Chalk provides a recording of the streamed material on each computer participating in the virtual session. This is beneficial on two levels: first, it provides an exact record of what was presented to the class, and second, it provides a time-synced record of the lecture including "board work" and audio.

A secondary benefit to the instructor is that having a recording of class presentations is an excellent method to later judge the quality of work and to find room for improvement. Many teachers and professors have their classes video-taped from time to time to assess their teaching. Silicon Chalk allows the instructor to assess all or any of his or her presentations, and also enables the instructor to obtain feedback from peers without them having to sit in on classes.

More Organized Lecture Material: A significant amount of preparation was required to make effective use of the technology. Although more prep time was required, the technology allowed the instructor to prepare more professional-looking, cleaner, and more organized lecture material. For example, the instructor often prepared problem statements and figures for many in-class example problems using Visio before class, resulting in more professional looking lectures. With practice and good preparation, the end result could significantly better than what students might be able to transcribe from board work. This prep work is also an investment, as after it is completed once, it can be used year after year.

The Use of Technology in the Classroom is Provocative: On more than one occasion, the instructor received feedback from the students indicating that they were pleased that someone was attempting to use modern technology in the classroom. It is the authors' opinion that students are better stimulated to learn when they see faculty members embracing modern teaching tools and using technology in the classroom. One danger in this, however, is that as the novelty wears off, students may find the technology distracting and be more tempted to use their computers for messaging and surfing - particularly when technical difficulties are encountered.

Legibility: One unforeseen difficulty that was encountered was the legibility of the instructor's handwriting on the tablet PC. Having used the tablet PC for only a short time before the start of the course, the instructor found it difficult to write as neatly on the PC as he could when using a pen and paper or a whiteboard / chalkboard. This problem was compounded, first by the fact that fine lines were difficult to see in the classroom, resulting in the conclusion that a heavier line 
weight was required for the pen, and second, by the fact that screen resolution was limited by bandwidth. To address these issues, a magnified image of the portion of the page that the instructor was working on was projected onto one screen while a broader image of two full pages was projected onto the second screen. Only the magnified image was streamed to the students' PCs through Silicon Chalk. Sitting on a stool with the tablet PC on a desk also helped with neatness.

Despite minor legibility shortcomings, Silicon Chalk offers an inherent advantage in that students can review their lecture recordings after class to discern difficult-to-read information whereas they would likely not transcribe unreadable information from the board to their handwritten notes.

Students Can Focus on Material Rather Than on Note Taking: When the system works as it is supposed to, students are able to focus more attention on material being presented rather than taking notes. Because of this, instructors can involve students at a higher level knowing those students are not encumbered with transcribing numbers and equations or copying intricate illustrations. This concept requires more preparation on the part of the instructor, though, as all examples must be prepared ahead of time. The instructor must also be prepared to ask questions of students so as to create an active-learning environment. If an instructor were to use this technology with lecture materials prepared for a conventional setting, the learning environment could quickly become passive, leading to a loss of students' attention.

Compounding the problem of losing students' attention was the fact that many of them had a computer sitting in front of them. Whenever there was downtime, or whenever their minds wandered, the students could simply check their e-mail, chat on-line, or surf the web. In fact, on several occasions students were observed working on computer projects totally unrelated to class material. Although Silicon Chalk includes the option of limiting the programs that students can and cannot use while in class, the instructor found it difficult to use this feature without interrupting the flow of the lecture. Furthermore, this feature is only effective when a student has started Silicon Chalk on his PC and has joined the virtual class session. The results of a study focusing on the engagement rates of students in class are presented later.

Network Polling and Questions: One of more attractive features of Silicon Chalk is the ability for students to ask questions over the network (either anonymously or otherwise) and the ability for the instructor to poll the students over the network. The benefits of this feature are obvious. First, students who may otherwise be too shy to ask questions openly can submit their queries anonymously and, as a result, may feel less inhibited about asking questions. Secondly, when polling the students, the instructor can often obtain more accurate and complete feedback to his questions since any one student won't know how the others are answering until the instructor reveals the results, if he or she chooses to do so. The instructor has the option of answering questions at the time that they are submitted or he or she can answer them off-line, outside of class. Similarly, students and the instructor can compose questions either in class or outside of class.

While this feature is truly revolutionary, the instructor found it difficult to implement in practice for two reasons. First, since only a portion of the class was using Silicon Chalk, the value of the 
feature was significantly diminished. Second, the aforementioned networking problems rendered the questioning and polling features almost useless. A few students mentioned verbally that they had submitted electronic questions during class only to realize that they never made it to the instructor's computer.

Networking Problems: Although substantial effort was made before the start of the quarter to make sure that networking issues were properly addressed, the requirements and settings are quite complex and the system seldom worked flawlessly. In most cases, there was a very noticeable lag between the time when material was displayed on the projectors and when it appeared on students' computers. In some cases, students experienced black-outs on their computers or a complete failure of the system. A few students commented that they were distracted by this time lag, especially when they were attempting to take notes on top of the instructor's media stream.

As was stated earlier, Silicon Chalk was originally developed with a wired network in mind. Version 3 of the software has wireless networking support built in, but even with this, the system was often sluggish. One of the first suggestions from Silicon Chalk was to use a wired network connection to the instructor's primary PC and set it in "multicast" mode. The instructor and UC technical support staff resisted the idea of using a wired connection to the instructor's PC because (1) the wire would have connected the instructor's PC to a different sub-net and (2) UC had made a significant investment in wireless infrastructure and wanted to make it work properly.

Silicon Chalk support made it very clear that when a wireless network is used, it has to be properly configured. Silicon Chalk performs much better on a "layered" network as opposed to a "flat" network. In a flat network, traffic from other classes or students can interfere with the Silicon Chalk stream. In a layered network, each classroom is separated from the network traffic, enabling the Silicon Chalk software to perform better. Early in the quarter, students were connecting to two or three different network access points depending on where they were sitting in the classroom. While it was initially thought that this would help since no single access point would be overwhelmed by the Silicon Chalk traffic, it quickly became apparent that information sent from one access point to another was being significantly delayed. A couple of weeks into the quarter, the signal strength of the access points was adjusted and a dedicated network ID was created so that all participants could connect to the same access point. This helped only marginally, though, as many of the students' computers automatically connected to the wrong network.

A third consideration is the content of the media that is being streamed. While Silicon Chalk worked very with PowerPoint presentations, it was slowed by the use of a tablet PC. When streaming a PowerPoint presentation, Silicon Chalk needs only to send copies of static images, but when streaming from a tablet PC, it continuously sends screen shots of the captured window, requiring a substantial amount of bandwidth. Reducing the resolution and color depth of the instructor's primary PC helped somewhat.

Finally, after several weeks it was noticed that the amount of bandwidth available as indicated in the Silicon Chalk software was significantly smaller than that advertised by the computers' 
operating systems. After discussing this with Silicon Chalk technical support, it was found that their software significantly limits the amount of available bandwidth that can be used. This is the result of a conservative strategy taken by Silicon Chalk developers to help mitigate problems with packet loss over the network. Silicon Chalk eventually provided UC with a software patch that, when installed, eased the restriction of bandwidth and improved the performance of the system.

Lack of Instructor Mobility: Using the tablet PC as a writing instrument limited the mobility of the instructor. This situation was worsened by the fact that a stool was used to help with penmanship on the tablet PC. In typical classes when a whiteboard or chalkboard is used, the instructor is able to move around the front of the classroom to a much greater extent, helping to engage students in the lecture. Even though the positive effects of being able to face the students while writing may have helped to offset this, the instructor definitely felt like his own energy level was much lower in this class as compared to other classes.

Lost Time: There were several instances throughout the quarter when the use of Silicon Chalk resulted in a loss of instructional time. During the first couple of classes, there was significant lost time as the instructor became comfortable using new methods of teaching, and the computers were fairly distracting to the students. Even after the novelty of the system wore off, there were a number of instances where time was lost opening files, waiting for the network, or when the instructor's computer would occasionally freeze or lock up entirely. During one lecture, the instructor had to abandon the use of the computers entirely when he realized that he had left the stylus to the tablet PC at home. On another occasion, he had to ask a student to leave class and purchase replacement batteries for the wireless microphone that he used. During a two-week observation period in the middle of the quarter there was a total of 15.5 minutes of technical timeouts. This total includes setup, teardown, and any time class was stopped to address problems during the session. This resulted in almost four minutes being lost per class period. It was critical that a technical support person from the college computing staff sat in on the classes for most of the quarter to help with technical issues that both the students and instructor encountered. Without this assistance, much more time would have been lost.

It required a substantial amount of time before each class period to set up the instructor's and students' computers, and an additional amount of time to pack up the equipment at the end of class. Since there was a class in the room before the class being discussed here, it was sometimes a challenge to start on time. This difficulty could be addressed, though, by scheduling classes in the early morning or by providing longer gaps between class sessions.

Student Attendance: This class was the first instance where the instructor made his notes directly available to students. In the past he has been concerned that making his notes available would be lead to a drop in attendance. In this case, however, he chose to make his notes available on-line in an effort to be fair to those students who decided not to use Silicon Chalk. In other words, the instructor felt that it would be unfair that a student who used Silicon Chalk and missed a class would be able to copy the recording from a friend while a student who chose not to use Silicon Chalk would not have that option. 
No problems with attendance were noted until approximately two to three weeks before the end of the quarter. It is estimated that after that time approximately $25-40 \%$ of the class was absent during any given lecture. It is speculated that as final exams approached and projects were due, the students identified this class as one that they could procrastinate in since all of the material was available on-line. Approximately four or five students missed almost the entire last three weeks of class.

Significant Financial Investment: Cost is a serious consideration in the use of this technology. As implemented in the current context, the instructor needed a tablet PC with wireless networking, a second computer with wireless networking, and approximately one wireless access point for every 10 to 15 students in the class. Each student needed a portable computer with wireless networking. Finally, licensing was required for Silicon Chalk and any other software that was used. This obviously amounted to a significant investment. In the case of the University of Cincinnati, each student already had a wireless laptop and the wireless networking infrastructure was already in place. As a result, the college's financial investment amounted to approximately $\$ 2,500$, including software licensing and the purchase of a tablet PC for the instructor.

Student Performance: Since the class size was small, no formal effort was made to correlate grades to the use of Silicon Chalk aside from the results presented in Section Five. No significant difference was noted in performance between those students using Silicon Chalk and those who did not. However, the grades reported for this class were the worst that the instructor has reported for this course in the 14 instances that he has taught it. While this is qualitative at best, since different examinations were used for the classes, etc., it is interesting and worthy of note.

Student Feedback: Shortly after the middle of the quarter, a short Likert Scale was distributed to the students to obtain feedback concerning their experiences with the class. Of the 21 students participating in the survey, 12 indicated that they used Silicon Chalk in the classroom. Of these 12 students, three indicated that they use Silicon Chalk outside of class. When one considers the significant cost of using this technology - both in terms of time and real dollars - it is disappointing that it was not utilized more outside of class. The remainder of the survey is summarized in Table 1.

\section{Engagement Rates:}

During the fifth and sixth weeks of the quarter, a study was conducted to evaluate the engagement rate of the students in the class. One of the authors observed the class and recorded when students were participating in class-related activities and when they were not.

\subsection{Procedure:}

The independent variable was the presence or absence of a laptop in class. Of the 24 students in the class, seven of them brought their laptops every day that they came to the class. These students were put into the experimental group for the study. The remaining 17 students were put 
into the control group. The dependent variables for this study were engagement rate, attendance, and student success. Attendance was taken for each class period. The non-engagement rate was recorded during the sessions. Non-engaged behaviors were marked using four different codes: $\mathrm{S}$ (Socializing), U (Uninvolved), W (Waiting), and C (Computer). S was used to describe a situation when two or more students were talking or engaging in some other form of communication. U was used when a student was not paying attention, such as sleeping, staring off into space, or working on something that was not related to the current class. W was marked when a student was waiting for something from the teacher, such as a handout or a topic change. $\mathrm{C}$ was used to describe when a student with a laptop was using applications other than Silicon Chalk, such as email or instant messaging. The engagement rate was calculated from this data. An examination was given at the end of the observation period and the results were used as a measure of student success.

Table 1: Results of a Student-Feedback Questionnaire

\begin{tabular}{|c|c|c|}
\hline Question / Statement & $\begin{array}{l}\text { Number of } \\
\text { Responses }\end{array}$ & Average \\
\hline $\begin{array}{l}\text { 1) How would you rate the overall experience of this class? } \\
(5=\text { Great, } 1=\text { Poor })\end{array}$ & 21 & 3.90 \\
\hline $\begin{array}{l}\text { 2) I feel that Silicon Chalk is an effective teaching tool? } \\
\text { ( } 5=\text { Agree Strongly, } 1=\text { Disagree Strongly) }\end{array}$ & 20 & 3.10 \\
\hline $\begin{array}{l}\text { 3) I make use of the Silicon Chalk Recordings that are posted on } \\
\text { the web site. ( } 5=\text { Routinely, } 3=\text { Occasionally, } 1=\text { Never) }\end{array}$ & 21 & 1.81 \\
\hline $\begin{array}{l}\text { 4) I make use of the PDF copies of the notes that are posted on } \\
\text { the web site. ( } 5=\text { Routinely, } 3=\text { Occasionally, } 1=\text { Never) }\end{array}$ & 21 & 2.95 \\
\hline $\begin{array}{l}\text { 5) I make use of the examples that are posted on the web site. } \\
(5=\text { Routinely, } 3=\text { Occasionally, } 1=\text { Never })\end{array}$ & 21 & 3.76 \\
\hline $\begin{array}{l}\text { 6) I make use of the old exams that are posted on the web site. } \\
(5=\text { Routinely, } 3=\text { Occasionally, } 1=\text { Never })\end{array}$ & 21 & 4.19 \\
\hline
\end{tabular}

\section{$\underline{5.2 \text { Results: }}$}

The mean values for the engagement rate, attendance rate, and exam scores are shown in Table 2. Recall that the control group consisted of those students who did not bring a laptop to class and therefore did not use the software program, and the experimental group was those students who brought a laptop and therefore had the opportunity to use the software program.

The behavior of the control group was evenly distributed between socializing, uninvolvement, and waiting. The experimental group spent most of their unengaged time playing on their computers or socializing. Therefore there was little or no waiting or uninvolvement in this group. The degree of socializing was about the same for both groups. This suggests that Silicon Chalk did not influence the amount of time a student spent socializing in class.

It should be noted that there was one student in the class who may have skewed the results. This student, who was in the experimental group, consistently came to class, sat in the back of the room, and played on his computer for the entire class period. During the two weeks of 
observation he did not once open the Silicon Chalk program or take notes. Including this student significantly deflated the engagement rate and exam scores (since he did poorly on the exam) of the experimental group. If his data were omitted from the results, the experimental group would have a much higher engagement rate and test score. However, the authors cannot exclude this data from the set because this student consistently brought his PC to class and therefore had the opportunity to use the software but chose not to.

Table 2: Results of Engagement Rate Study

\begin{tabular}{|r|c|c|c|}
\hline & $\begin{array}{c}\text { All } \\
\text { Students }\end{array}$ & $\begin{array}{c}\text { Control } \\
\text { Group }\end{array}$ & $\begin{array}{c}\text { Experimental } \\
\text { Group }\end{array}$ \\
\hline Average Engagement Rate & $80.7 \%$ & $82.0 \%$ & $77.8 \%$ \\
\hline Average Attendance Rate & $89.6 \%$ & $91.2 \%$ & $85.7 \%$ \\
\hline Average Exam Score & $56.9 \%$ & $55.6 \%$ & $59.9 \%$ \\
\hline
\end{tabular}

\subsection{Discussion:}

The engagement rate was higher for the control group by $4.2 \%$ and the attendance rate was higher for the control group by $6.5 \%$. Although this seems slightly consistent there are too many other factors involved to establish a relationship between Silicon Chalk and student behavior. These factors include not having two groups the same size and poor exam grades for the entire class.

\section{Suggestions and Future Plans:}

While the UC College of Engineering is not planning to widely implement the use Silicon Chalk in the near future, the authors intend to select another section of Basic Strength of Materials within the next year to further investigate its potential advantages. In future trials, however, the instructors intend to use a dedicated access point for the students - one that is not connected to the internet but provides only local networking to facilitate the use of Silicon Chalk. This should help alleviate the problems with network bandwidth that were experienced during the first trail and may help eliminate some of the distractions that in-class internet access provides. It is hoped that moving to an 802.11g network will also help alleviate bandwidth issues. Additionally, the authors intend schedule the class during an early morning period so that the room will be empty before class to help avoid lost time due to set-up.

In future trials, the authors also intend to focus more on student performance, learning styles, and attitudes. It is hoped that the class will be broken into a Silicon Chalk section and control section that will be taught by the same instructor, complete the same assignments, and take the same exams. With these two groups of approximately 20 students, a more meaningful statistical analysis can be made. Next, the effects on student attitudes will be more closely evaluated by giving three or four surveys throughout the quarter. The authors hope to gain insight into the effects of using Silicon Chalk on student stimulation and retention. Finally, personality types and learning styles will be assessed using Meyers-Briggs Type Indicators and Learning Styles Inventory questionnaires and will be correlated to both performance and attitude changes. 
Finally, the potential that this technology holds for distance learning is enormous. The idea of using a system where students can participate actively in a lecture from anywhere broadband networking is available is quite alluring and warrants investigation. Following a more successful classroom trial of the system, the authors hope to investigate this possibility.

\section{Conclusion:}

While there is no doubt that this technology has promise in education, there are many questions remaining to be answered before it is accepted into the main stream, particularly in engineering curriculums. Will it actual help students learn better? Will it help with retention in engineering? Will it help save money? Does it help with students' attitudes?

The streaming technology discussed in this paper is at its beginning stages in engineering education, particularly with regard to the use of wireless networking and tablet computers. As a result, it may be better suited to classes where PowerPoint presentation can be used effectively or on wired networks. In the situation documented (using a tablet PC and a wireless network) the system did not perform adequately. One can speculate that the bandwidth problems that were encountered would have been exacerbated had more students participated by using Silicon Chalk.

\section{Bibliography:}

1. Alexander, S. (2001). "E-Learning developments and experiences." Education + Training, 43 (4/5), 240-248.

2. Bates, A. (1997). "Restructuring the university for technological change," What Kind of University?, Proceedings of The Carnegie Foundation for the Advancement of Teaching, (1997), London.

3. Delisio, E. R., (2004), "Author Says Technology Brings False Promises to Schools," Education World Web Page, http://www.education-world.com/

4. Arnold, M. (1999). "Mainstreaming the digital revolution.” Higher Education Quarterly, 53 (1), 49-64.

5. Baseheart, T. M., Miller, R. A., Bowers, M. T., Ioannides, A., Swanson, J. A., and Eckart, R. (2002) "Teaching Strength of Materials Using Web-Based Streaming Video and Interactive Video Technologies," Proceedings of the 2002 American Society for Engineering Education Annual Conference \& Exposition, American Society for Engineering Education, Montréal, Québec , Canada, June 16-19, 2002

\section{CAROLINE R. KAYSER}

Caroline R. Kayser is a Graduate Research Assistant., U.S. Dept. of Education GAANN Fellow and PhD Candidate in the Dept. of Civil \& Environmental Engineering at the University of Cincinnati

JENNIFER J. AMRINE

Jennifer J. Amrine is a Graduate Research Assistant., U.S. Dept. of Education GAANN Fellow and PhD Candidate in the Dept. of Civil \& Environmental Engineering at the University of Cincinnati

JAMES A. SWANSON

James A. Swanson is an Assistant Professor in the Dept. of Civil \& Environmental Engineering at the University of Cincinnati 